\title{
Identification of Gram-negative bacteria in histological sections using Sandiford's counterstain
}

\section{R. E. LEAVER, B. J. EVANS, AND B. CORRIN Department of Morbid Anatomy, St. Thomas's Hospital Medical School, London SE1 7EH}

There exist many methods for the application of the Gram stain to histological sections, and with all of them there is generally no difficulty in recognising Gram-positive organisms. However, with most of the well-recognised methods Gram-negative bacteria are difficult to distinguish from the background. Twort's method distinguishes Gram-negative bacteria from the background but is relatively timeconsuming (Cook, 1974), and we therefore turned our attention to Sandiford's modification of the Gram stain (Cruikshank et al., 1975). Sandiford's counter stain was designed for use with bacteriological smears but appeared eminently suitable for applying to paraffin sections. In brief, the modification consists of staining bacteria which are not Gram-positive with pyronin and using malachite green as a counterstain. The resultant black and red organisms (Gram-positive and -negative respectively) both contrast well with the blue-green background and are easily recognisable. We have used this method for the last five years and have found it most helpful in the recognition of Gramnegative bacteria. A comparison of Twort's and Sandiford's modifications of the Gram stain shows that the results are virtually indistinguishable, but we prefer the Sandiford method because it is quicker. Recently, Sowter and McGee (1976) have described a Gram-methyl green-pyronin-light green method which gives results comparable to the GramSandiford technique but again the latter stain acts much more quickly. No doubt some histopathology laboratories already use the Sandiford modification but we are unable to find any description of it in the standard histology manuals and believe that it deserves wider recognition.

\section{Method}

1 Dewax in xylol

2 Absolute alcohol rinse

3 Distilled water rinse

$41 \%$ aqueous crystal violet or methyl violet, 3 min

5 Rinse in tap water

Received for publication 17 November 1976
6 Gram's iodine, $3 \mathrm{~min}$

7 Rinse in tap water, blot dry, differentiate in equal parts acetone and absolute alcohol

8 Wash in running tap water 2-3 min

9 Counterstain with Sandiford's stain 2 min

10 Rinse in tap water

11 Blot dry, differentiate for a few seconds, and dehydrate in absolute alcohol

12 Clear in xylol and mount

Sandiford's stain

Malachite green

Pyronin

Distilled water

$0.05 \mathrm{~g}$

$0 \cdot 15 \mathrm{~g}$

$100 \mathrm{ml}$

\section{Result}

Gram-positive organisms are purple-black, Gramnegative organisms red, and background bluegreen (Figure).

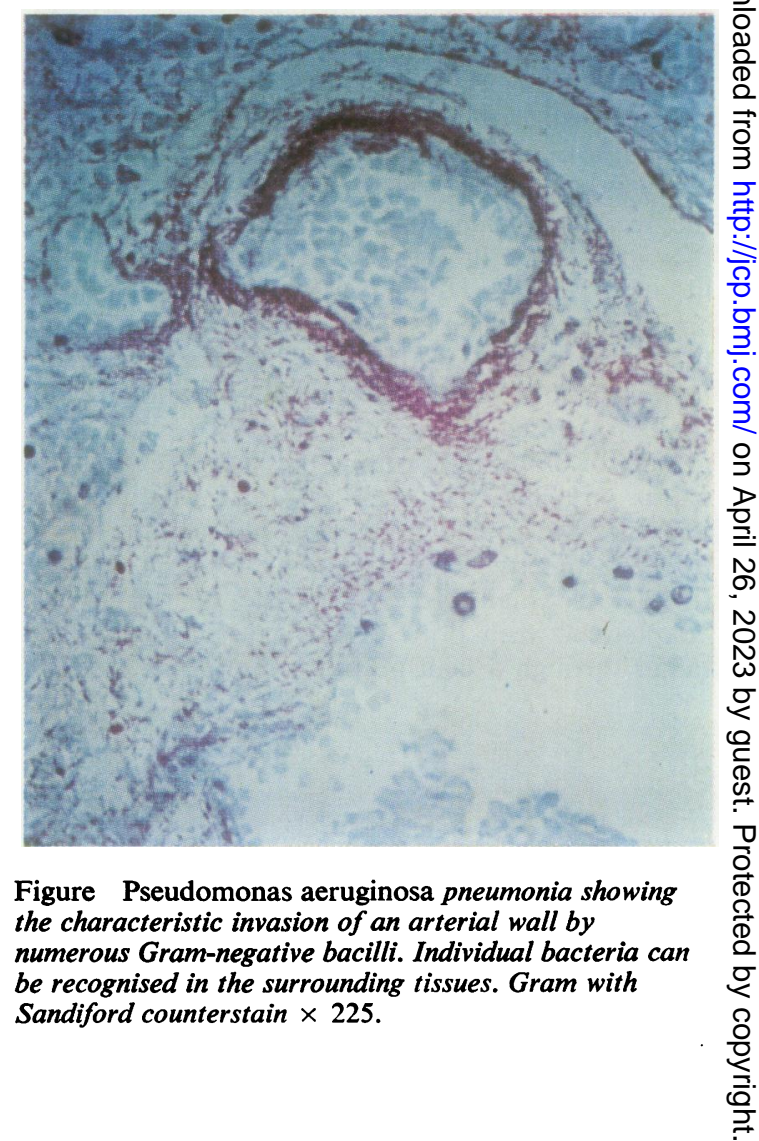




\section{References}

Cook, H. C. (1974). Manual of Histological Demonstration Techniques, p. 122. Butterworths, London.

Cruikshank, R., Duguid, J. P., Marmion, B. P., and Swain, R. H. A. (1975). Medical Microbiology, 12th edition, vol. 2, p. 36. Churchill-Livingstone, Edinburgh and London.

Sowter, C. and McGee, Z. A. (1976). Evaluation of a new technique for the demonstration of gonococci and other micro-organisms in host cells. Journal of Clinical Pathology, 29, 433-437.

\section{Letters to the Editor}

\begin{abstract}
Demonstration of bacterial capsular polysaccharide in CSF by counter immunoelectrophoresis
\end{abstract}

The demonstration of bacterial capsular polysaccharide in cerebrospinal fluid (CSF) by counter immunoelectrophoresis (CIE) has provided a useful addition to the usual diagnostic tests (Greenwood et al., 1971; Coonrod and Rytel, 1972; Higashi et al., 1974; Myhre, 1974 ), particularly in patients who have been given antibiotics. Unfortunately, with group B meningococci the method often fails because of the poor precipitating activity of commercially available antisera (Tobin and Jones 1972). However, group B meningococci share a capsular antigen with Escherichia coli K1 (McCracken, 1976) which can be used as a control to validate the activity of antimeningococcal group $\mathbf{B}$ antisera.

Equine group $B$ meningococcal antiserum is available on request from $\mathrm{Dr}$ John B. Robbins of the Department of Health and Welfare, USA ${ }^{\mathbf{1}}$, but, according to the accompanying instructions, the antiserum is unsatisfactory when CIE is carried out using agarose as supporting media. Also, it has been found with rabbit antimeningococcal group $B$ antisera that reaction with $E$. coli $\mathrm{K} 1$ antigen may be apparent only when using modified electrolyte systems in CIE (Fallon and McIllmurray, 1976).

I should like to draw the attention of those who use the method that the equine globulin kindly supplied by Dr. Robbins does give precipitation (to titre) with

\footnotetext{
1John B. Robbins, MD,

Department of Health, Education, and Welfare,

Food and Drug Administration, Bldg 29, Room 120, 8800 Rockville Pike, Bethesda, Maryland, USA
}

purified $\mathrm{K} 1$ polysaccharide, also provided, when CIE is performed using ready prepared agarose plates (Millipore, UK) in barbitone buffer, $\mathrm{pH} 8 \cdot 6$, at $12 \mathrm{~mA}$ for one hour. Three commercially available antimeningococcal antisera (Wellcome Polyvalent A-D, Wellcome group B, and Difco Polyvalent A-D) did not form a precipitate with the K1 antigen or with a specimen of CSF from a patient with established group $B$ meningococcal meningitis. However, dilutions of up to 1 in 8 of this CSF sample did precipitate with neat horse antiserum provided by Dr Robbins. A sample of neat CSF (but not in dilution) from a patient with established group $\mathrm{C}$ meningococcal meningitis cross-reacted with the equine globulin, a finding also observed by Dr Robbins. Therefore, long-term usage will be required to determine the absolute specificity of this equine globulin.

These preliminary findings suggest that the sensitivity of CIE for the detection of group B meningococcal antigen would be improved by using the antiserum provided by Dr. Robbins. However, in neonates CIE alone will not differentiate between $E$. coli $\mathrm{K} 1$ and group B meningococcal meningitis.

\section{References}

Coonrod, J. D. and Rytel, M. W. (1972). Determination of aetiology of bacterial meningitis by counter-immunoelectrophoresis. Lancet, 1, 1154-1157.

Fallon, R. J. and McIllmurray, M. B. (1976). Escherichia coli K1 (Letter). Lancet, 1, 201.

Greenwood, B. M., Whittle, H. C., and Dominic-Rajkovic, O. (1971). Countercurrent immunoelectrophoresis in the diagnosis of meningococcal infections. Lancet, 2, 519-521.

Higashi, G. I., Sippel, J. E., Girgis, N. I., and Hassan, A. (1974). Counterimmuno- electrophoresis: an adjunct to bacterial culture in the diagnosis of meningococcal meningitis. Scandinavian Journal of Infectious Diseases, 6, 233-235.

McCracken, G. H. Jr. (1976). Rapid identifcation of specific etiology in meningitis. Journal of Paediatrics, 88, 706-708.

Myhre, E. B. (1974). Rapid diagnosis of bacterial meningitis: demonstration of $\frac{\rho}{\supset}$ bacterial antigen by counterimmuno- $\vec{\theta}$ electrophoresis. Scandinavian Journal of Infectious Diseases, 6, 237-239.

Tobin, B. M. and Jones, D. M. (1972) Immunoelectroosmophoresis in the diag nosis of meningococcal infections. Journal of Clinical Pathology, 25, 583-585.

JOHN EDWARD CORKILL Bacteriology Department, Liverpool Royal Infirmary

Starch serum agar-a differential medium for the isolation of Corynebacterium vaginale ('Haemophilus' vaginalis)

Recently, many reports have been published on the bacteriological and clinical aspects of infection with Corynebacterium vaginale, a Gram-variable rod first isolated from the genitourinary tract by Leopold (1953). There is also increasing evidence that the organism may cause vaginitis and cervicitis in women and urethritis in men (Dunkelberg and Woolvin, 1963; Lewis et al., 1972; Åkerlund and Mårdh, 1974).

Casman's blood agar (Casman, 1947; Dukes and Gardner, 1961) is generally used for its isolation, but colonial distinction from other genitourinary flora is often difficult. Dunkelberg's peptone starch dextrose (PSD) agar (Dunkelberg et al., 1970) gives better results but colonydifferentiation on the primary culture plates remains a problem.

A new differential medium, starch serum agar (SS), has been devised and found to give consistent results. Its 